Володимир Миколайович Шемаєв (доктор військових наук, професор) ${ }^{1}$ Ігор Олександрович Ляшенко (кандидат військових наук) ${ }^{2}$ Сергій Сергійович Стефанцев ${ }^{2}$

${ }^{1}$ Національний інститут стратегічних досліджень, Київ, Украӥна

${ }^{2}$ Київський Національний економічний університет імені Вадима Гетьмана, Киӥв, Украӥна

\title{
ФОРМАЛІЗАЦІЯ ВІДКРИТОЇ ГАЛУЗІ ЗНАНЬ РОЗПОДІЛЕНОЇ СИСТЕМИ УПРАВЛІННЯ
}

При управлінні прочесами в різних галузях, особливо в інформаційній сфері, досить часто виникає потреба в прийнятті рішення в слабко структурованих динамічних ситуаціях, коли параметри (значення змінних), закони та закономірності розвитку ситуації описуються не кількісно, а якісно. При цььому виникає унікальна ситуація, коли зміни ї̈ структури дуже важко передбачити. Тому в статті розглядаються питання використання експертами та аналітиками власного досвіду та інтуїії. В таких ситуачіях застосовується суб 'єктивна модель, яка називається когнітивною картою.

Метою даної статті $\epsilon$ аналіз розроблення та використання відкритої інтерактивної інтелектуальної системи реального часу з неповною інформацією. Ця система повинна містити засоби добування нових знань з даних, щзо поступають в неї. Формальна модель иієї системи повинна містити засоби для бази знань, щзо постійно змінюється, та правил виведення, по яких робляться припущення.

Автори розглядають підхід щ̧одо розроблення та використання концепції побудови аргументаційної системи підтримки прийняття рішень в конфліктних ситуаціях.

Використання зазначеної концепиії спрямована на виявлення індивідуально значимих чинників, норм, переваг, аргументів, альтернатив і стратегій вибору.

Ключові слова: система управління, когнітивна карта, формалізація, немонотонність, інтерактивна інтелектуальна система реального часу, квазіаксіомотична теорія.

\section{Вступ}

В процесі управління виникає потреба в прийнятті рішення в слабко структурованих динамічних ситуаціях, коли параметри (значення змінних), закони та закономірності розвитку ситуації описуються не кількісно, а якісно. Прикладом такої ситуації може бути забезпечення живучості систем управління, коли виклики як зовнішнього, так внутрішнього характеру не мають структурованого та чіткого обрису. Унікальність даних ситуацій полягає в тому, що вони супроводжуються змінами їі структури, які дуже важко передбачити. Тому з метою прийняття рішення в умовах дефіциту точної кількісної інформації експерти та аналітики вимушені опиратися на власний досвід та інтуїцію застосовуючи для прийняття рішення в якості моделі динамічної ситуації суб'єктивну модель, що побудована на оцінках аналітиків. Таку суб'єктивну модель слабко структурованої динамічної ситуації називають когнітивною картою.

Постановка проблеми. Діяльність експертів та аналітиків, що направлена на дослідження ситуації та прийняття рішення за допомогою когнітивних карт являє собою методологію - логіко-часову структуру застосування різноманітних методів та прийомів побудови когнітивної карти, іiі параметризації, прогнозування розвитку ситуацій, верифікації, коректування когнітивної карти та прийняття рішення.

Необхідно відмітити, що при когнітивному моделюванні величезна доля спроб формалізувати слабко структуровані процеси традиційними математичними методами закінчувалась тим, що моделі ставали настільки абстрактними, що не могли відобразити дійсність. Тому завданням цієї роботи є розглянути підходи, що формалізують відкриту галузь знань в процесі когнітивного моделювання.

Можна виділити дві проблеми формалізації процедури аргументації: зовнішню і внутрішню. Зовнішня проблема полягає в прийнятті, або відкиданні припущень, на основі деякої множини аргументів, та побудові логічного висновку, на основі прийнятої множини припущень. Внутрішня проблема полягає в прийнятті рішення щодо висновків - які слід робити на наступному кроці. Це означає, що, окрім знань про проблемну область, аргументаційна система підтримки прийняття рішень повинна відображати знання про себе саму й мати засоби управління вибором правил виведення, тобто - метаправил для зміни правил виведення. Такі метаправила стають правилами самомодифікації множини припущень для прийняття рішень. Тоді процес вироблення припущень повертається до попередніх кроків і станів, відмовляючись від деяких припущень й 
аргументів і повторення процесу вироблення припущень знову, 3 урахуванням нових аргументів. Застосування цих правил веде до видалення деяких припущень i аргументів 3 відповідних множин i прийняття нових припущень.

Враховуючи вищесказане, аргументаційну систему підтримки прийняття рішень можна охарактеризувати як відкриту інтерактивну інтелектуальну систему реального часу 3 неповною інформацією [1], яка повинна містити засоби добування нових знань 3 даних, що поступають в неї, і реалізовувати немонотонне виведення. Формальна модель цієї системи повинна містити засоби для бази знань, що постійно змінюється, та правил виведення, по яких робляться припущення.

Аналіз останніх досліджень і публікацій. Різні підходи до формалізації немонотонних припущень знайшли своє відображення в немонотонних логіках [2-9]. Немонотонність в цих логічних системах пов'язана 3 тим, що при отриманні додаткової інформації переглядаються раніше зроблені висновки, які стають несумісними 3 новим, повнішим описом ситуації. Практичні аспекти реалізації немонотонних логічних міркувань були розглянуті в роботі Дойла [10], там же запропоновані інструментальні засоби (інтерпретатор рефлексіі), що реалізовують процедури управління при немонотонному виведенні.

\section{Виклад основного матеріалу дослідження}

В задачах управління ситуаціями в конфліктах об'єктом дослідження слід вважати конфлікт, а об'єктом управління - ситуацію, що розвивається в ході конфлікту. Під ситуацією слід розуміти стан системи та зовнішнього середовища у конкретний момент часу. При цьому, стан системи сукупність значень, що описують параметри системи у конкретний момент часу. У конфлікті, де взаємодіють декілька систем: системи сторін учасників конфлікту та системи, що виступають в якості зовнішнього середовища по відношенню до них, будь-яка система 3 точки зору системного аналізу в конкретний момент часу може задаватися наступними параметрами:

- складом, що визначає «хто» входить в систему;

- цільовими функціями елементів системи «Хто що хоче»;

- якістю системи та / або їі елементів - "хто на скільки корисний";

- умовами функціонування системи та/або іiі елементів - "хто як функціонує";

- інформованістю системи та/або їі елементів «Хто що знає»;

- структурою системи - «Хто 3 ким взаємодіє»;

- допустимими множинами стратегій системи та/або їі елементів - «хто що може».

3 цих позицій, під управлінням ситуацією у воєнному конфлікті слід розуміти здійснення сукупності впливів, обраних з множини можливих на підставі наявної інформації та направлених на підтримку або зміну протягом визначеного часу та відповідно до обраної мети параметрів систем, що розглядаються в операції. При цьому, задачу підтримки прийняття рішення по управлінню ситуацією у конфлікті слід розглядати як задачу розробки пропозицій щодо стратегії переводу ситуації 3 поточного стану в цільовий 3 використанням моделі конфлікту.

В якості методологічного підходу щодо дослідження воєнного конфлікту 3 метою підтримки прийняття рішення на управління ситуацією, що в ньому розвивається, пропонується використовувати методологію когнітивного моделювання. Методологія когнітивного моделювання $\epsilon$ одним із напрямків штучного інтелекту, де ставиться та вирішується задача автоматизації окремих функцій, що реалізуються людиною в процесі пізнання. Вона базується на інтеграції системного, синергетичного, когнітивного та сценарного підходів.

Подібні системи, принципово відкриті для навчання, здатні до перебудови своїх аксіом, синтаксичних правил i правил виведення, розроблялися i досліджувалися у рамках ситуаційного управління [11]. Для їх формалізації Д.А.Поспєловим було запропоноване поняття семіотичної моделі, яка визначається як

$$
\mathrm{C}=<\mathrm{M}, \mathrm{P}, \mathrm{A}, \mathrm{R}, \psi_{\mathrm{M}}, \psi_{\mathrm{P}}, \psi_{\mathrm{A}}, \psi_{\mathrm{R}}>
$$

де $\mathrm{M}$ - множина базових елементів, $\mathrm{P}$ синтаксичні правила, А - аксіоми, R - правила виведення формальної теорії, $\psi_{\mathrm{M}}, \psi_{\mathrm{P}}, \psi_{\mathrm{A}}, \psi_{\mathrm{R}}$ метаправила, що змінюють М, Р, A, R відповідно [11]. Концепція семіотичних моделей розвивається в ситуаційному управлінні і моделюванні в рамках напряму, що дістав назву прикладної семіотики [12-15], при цьому логічний апарат i інструментальні засоби управління, що використовуються для виведення, відрізняються великою різноманітністю й істотно залежать від класу завдань, що вирішуються та проблемної області.

Концепція відкритих інтелектуальних систем послідовно розроблялася Фіном [16]. У цих роботах було уточнено формальне визначення інтелектуальної інформаційної системи та сформульовані основні принципи створення інтелектуальних систем, що містять бази даних 3 неповною інформацією та відкриті бази знань, в яких формалізуються як достовірні, так i правдоподібні припущення, для управління якими використовуються металогічні засоби. У подальшому сформульована методологія побудови інтегрованих інтелектуальних систем типу ДСМ, в яких передбачається комбінування прямих, зворотних, монотонних і немонотонних процедур, що реалізовують як достовірні, так і правдоподібні припущення. ДСМ-система аналізує емпіричні дані та породжує гіпотези про причиннонаслідкові залежності у базі даних 3 неповною інформацією, які приймаються (чи відкидаються) 
на підставі критерію достатньої основи прийняття гіпотез, поповнюючи базу знань в процесі діалогу. Відкритість такої системи обумовлена тим, що інструментальні засоби та база знань системи налаштовується на предметну область за допомогою специфікації аксіом структури даних і аксіом предметної області, а також додавання металогічних засобів управління припущеннями відносно відкритої предметної області. Для формального опису відкритої системи знань Фіном було введено поняття квазіаксіоматичної теорії (KAT) [17].

Квазіаксіоматична теорія має вигляд:

$$
\mathrm{T}=<\Sigma, \Sigma^{\prime}, \mathrm{R}>
$$

де $\Sigma$ - множина аксіом, що частково характеризують проблемну область, $\Sigma^{\prime}$ - відкрита множина напівфактів (напівфакт являє собою факт або гіпотезу), що поповнюється в процесі роботи, $\mathrm{R}=\mathrm{R}_{\mathrm{r}} \cup \mathrm{R}_{\mathrm{p}}^{\prime}$ - об'єднання множини правил достовірного (дедуктивного) виведення $\mathrm{R}_{\mathrm{r}}$ та множини правил правдоподібного виведення $\mathrm{R}_{\mathrm{p}}{ }^{\prime}$. Кожне застосування правил правдоподібного виводу змінює стан КАТ, який визначається як

$$
\mathrm{T}_{\mathrm{n}}=<\Sigma_{\mathrm{n}}, \Sigma_{\mathrm{n}}^{\prime}, \mathrm{R}_{\mathrm{n}}>
$$

$$
\mathrm{T}_{\mathrm{o}}=<\Sigma_{\mathrm{o}}, \Sigma_{\mathrm{o}}^{\prime}, \mathrm{R}_{\mathrm{o}}>
$$

$\epsilon$ початковий стан КАТ, до якої ще не застосовувалися правила правдоподібного виводу.

На основі цієї методології пропонується побудова формальної моделі аргументаційної системи підтримки прийняття рішень як квазіаксіоматичної аргументаційної теорії (КААТ), що формалізується засобами логіки аргументації.

На рис.1 представлена загальна концепція аналізу та підтримки прийняття рішень в когнітивних конфліктах.

Концептуальна реконструкція суб'єктивних представлень спрямована на виявлення індивідуально значимих чинників, норм, переваг, аргументів, альтернатив і стратегій вибору. Для добування та представлення суб'єктивних уявлень про структуру конфліктної ситуації в системі управління планується використовувати метод концептуальної реконструкції, заснований на парадигмі "суб'єктного аналізу даних", при якому структура особових представлень відбивається на концептуальну схему когнітивного простору особи. Концептуальна реконструкція знаходить своє відображення в репрезентації суб'єктивних представлень: побудові когнітивних концептуальних моделей.

де $\Sigma_{\mathrm{n}}, \Sigma_{\mathrm{n}}^{\prime}$ - відповідно $\mathrm{n}-\mathrm{i}$ стани бази знань i бази напівфактів, $\mathrm{n}$ - номер кроку застосувань правил правдоподібного виводу. Тоді при $\mathrm{n}=0$

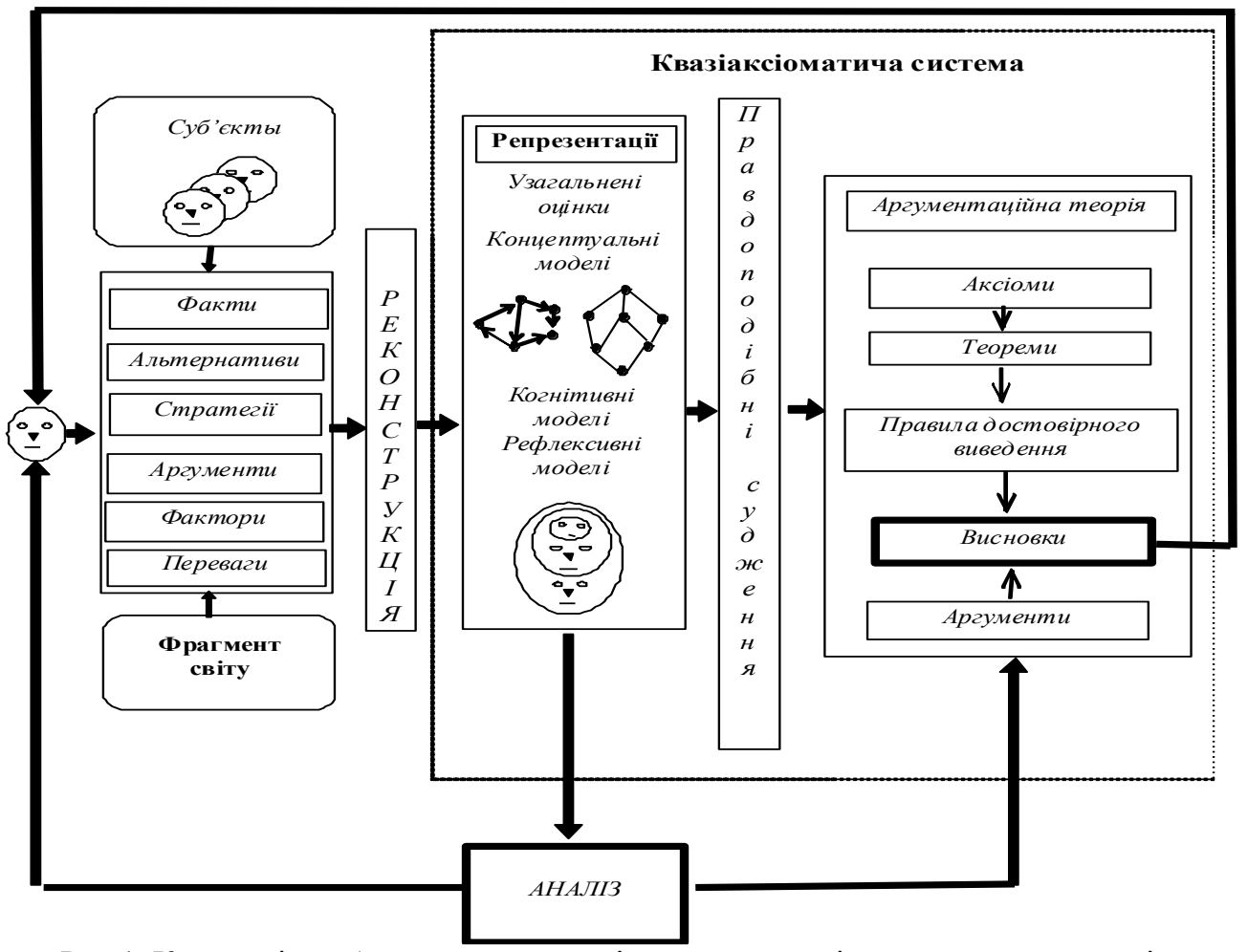

Рис.1. Концепція побудови аргументаційної системи підтримки прийняття рішень в конфліктних ситуаціях.

Суб'єктивні представлення, зокрема, деякі цінності, переваги, міркування вигоди, моральності та ін. можуть служити нормами, якими регулюється поведінка суб'єктів конфлікту в ситуації вибору при ухваленні рішення. Для моделювання поведінки в ситуації вибору використовуються методи побудови моделей 
рефлексій поведінки, що регулюється відібраною частково впорядкованою множиною норм.

Основним засобом підтримки прийняття рішення пропонується аргументація. Ця концепція покладена в основу розробки архітектури аргументаційної системи підтримки прийняття рішень, яка формалізується засобами квазіаксіоматичної аргументаційної теорії.

\section{Висновки і перспективи подальших досліджень}

В роботі розглянуто методологію побудови формальної моделі аргументаційної системи підтримки прийняття рішень - як квазіаксіоматичної аргументаційної теорії (КААТ), що формалізується засобами логіки аргументації в рамках концепції аналізу та підтримки прийняття рішень в когнітивних конфліктах як відкритої інтерактивної інтелектуальної системи реального часу 3 неповною інформацією, що містить засоби добування нових знань 3 даних, які надходять до неї, i реалізовує немонотонне виведення. Саме такою системою в майбутньому буде розподілена система управління в інформаційній сфері як спеціального призначення (виконує завдання в якійсь одній сфері, чи в інтересах якоїсь корпорації чи служби) так i регіонального чи глобального масштабу.

\title{
Jimepamypa
}

1. Таран T.А. Аналіз i моделювання когнітивних конфліктів // Праці 2-ї міжнародної конференції "Когнітивний аналіз і управління розвитком ситуацій". Т. 2. /Таран Т.А. - М.: ІПУ РАН, 2002. С. 96-119. 2. Brewka C. Логический поход к искусственному интеллекту: От классической логики к логическому программированию. М., 1990. Гл. 4; Brewka C, DixJ., Konolige K. Nonmonotonic Reasoning: An Overview. Stanford, 1995. 3. Бидой Н., Хулл Р. (1989) «Минимализм, оправдание и немонотонность в дедуктивных базах данных», Журнал Компьютерных и Системных Наук 38: 290-325. 4. Брюка Г. (1991). Немонотонное рассуждение: логические фонды здравого смысла. Издательство Кембриджского университета. 5. Брюка Г., Дикс Дж., Конолидж К. (1997). Немонотонное Рассуждение - Обзор. Публикации CSLI, Стэнфорд. 6. Кэдоли М., Шэерф М. (1993) «Обзор сложности заканчиваются для немонотонных логик» Журнал Логического Программирования 17: 127-60. 7. Донини Ф. М., Ленцерини М., Нарди Д., Пирри Ф., Шэерф М. (1990) «Немонотонное рассуждение», Artificial Intelligence Review 4: 163-210. 8. Гинсберг М.Л., редактор (1987) Чтения в Немонотонном Рассуждении. Лос

Альты СА: Морган Кофман. 9. Horty J.F., 2001, «Немонотонная Логика», в Goble, Лу, редакторе, Справочнике Блэквелла по Философской Логике. Блэквелл. 10. McDermott, Doyl J. Nonmonotonic logic I // Artificial Intelligence. 1980. V. 13. P. 14 - 72. 11. Поспелов Д.А. Ситуационное управление: теория и практика / Поспелов Д.А. - М.: Наука, 1986. 288 стр. 12. Поспелов Д.А. Принципы ситуационного управления // Изв. АН СССР. Техническая кибернетика. - 1971. - № 2. - С. 10-17. 13. Клыков Ю.И. Ситуационное управление большими системами / Клыков Ю.И. - М.: Энергия, 1974. - 134 с. 14. Поспелов Д.А. Ситуационное управление. Теория и практика / Поспелов Д.А.- М.: Наука, 1986. - 288 c. 15. Osipov G.S. Semiotic Modeling: An Overview//In [4], pp. 51-72. 16. Финн В. К. Искусственный интеллект: методология, применения, философия = Artificial intelligence: methodology, applications, philosophy / науч. ред. М. А. Михеенкова. М.: КРАСАНД, 2011. 447 с. 17. Финн В.К. Правдоподобные рассуждения в интеллектуальных системах типа ДСМ. Итоги науки и техники. Информатика. Т. 15. М: 1991. с.54-101.

\section{ФОРМАЛИЗАЦИЯ ОТКРЫТОЙ ОБЛАСТИ ЗНАНИЙ РАСПРЕДЕЛЕННОЙ СИСТЕМЫ УПРАВЛЕНИЯ}

\author{
Владимир Николаевич Шемаєв (доктор военных. наук, профессор) ${ }^{1}$ \\ Игорь Александрович Ляшенко (кандидат военных. наук) ${ }^{2}$ \\ Сергей Сергеевич Стефанцев ${ }^{2}$
}

\section{${ }^{1}$ Национальный институт стратегических исследований, Киев, Украина ${ }^{2}$ Киевский национальный экономический университет имени Вадима Гетьмана, Киев, Украина}

При управлении прочессами в различных отраслях, особенно в информационной сфере, достаточно часто возникает потребность в принятии решения в слабо структурированньх динамических ситуациях, когда параметры (значения переменных), законы и закономерности развития ситуации описываются не количественно, а качественно. При этом возникает уникальная ситуация, когда изменения ее структуры очень трудно предсказать. Поэтому в статье рассматриваются вопросы использования экспертами и аналитиками собственного опыта и интуиции. В таких ситуациях применяется субъективная модель, которая называется когнитивной картой.

Целью данной статьи является анализ разработки и использования открытой интерактивной интеллектуальной системь реального времени с неполной информацией. Эта система должна содержать средства добычи новых знаний из данных, поступающих в нее. Формальная модель этой системы должна содержать средства для базы знаний, которые постоянно меняется, а также правила вывода, по которым делаются предположения.

Авторь рассматривают подход $\kappa$ разработке и использованию концепции построения аргументациинной системы поддержки принятия решений в конфликтных ситуаџиях. 
Использование указанной концепции направлено на выявление индивидуально значимых факторов, норм, предпочтений, аргументов, альтернатив и стратегий выбора.

Ключевые слова: система управления, когнитивная карта, формализация, немонотонность, интерактивная интеллектуальная система реального времени, квазиаксиомотическая теория.

\title{
FORMALIZATION OF THE OPEN KNOWLEDGE AREA OF THE DISTRIBUTED CONTROL
} SYSTEM

\author{
Volodymyr Shemaiev (doctor of military sciences, professor) ${ }^{1}$ \\ Ihor Liashenko (Candidate of Military Sciences) ${ }^{2}$ \\ Serhii Stefantsev ${ }^{2}$ \\ ${ }^{1}$ The National Institute for Strategic Studies, Kyiv, Ukraine \\ ${ }^{2}$ Kyiv National Economic University named after Vadym Hetman. Kyiv. Ukraine
}

When managing processes in various industries, especially in the information sphere, quite often there is a need for decision making in poorly structured dynamic situations when parameters (values of variables), laws and patterns of development of a situation are described not quantitatively but qualitatively. In this case, a unique situation arises when changes in its structure are very difficult to predict. Therefore, the article discusses the use of experts and analysts own experience and intuition. In such situations, a subjective model is used, which is called a cognitive map.

The purpose of this article is to analyze the development and use of an open interactive real-time intelligent system with incomplete information. This system should contain the means of extracting new knowledge from the data entering it. The formal model of this system should contain the means for the knowledge base, which are constantly changing, as well as the inference rules by which assumptions are made.

The authors consider the approach to the development and use of the concept of building an argumentation decision support system in conflict situations.

The use of this concept is aimed at identifying individually significant factors, norms, preferences, arguments, alternatives, and selection strategies.

Keywords: control system, cognitive map, formalization, non-monotonic, interactive real-time system, quasi-axiomatic theory.

\section{References}

1. Taran T.A. Analyzes and Models of Cognitive Conflicts // Proceedings of the International Conference "Cognitive Analysis and Management of Situation Development". V. 2. / Taran, T.A. M .: IPU RAS, 2002. S. 96-119. 2. Brewka S. Logical approach to artificial intelligence: From classical logic to logical programming. M., 1990. Ch. four; Brewka S, DixJ., Konolige K. Nonmonotonic Reasoning: An Overview. Stanford, 1995. 3. Bidoy N., Hull R. (1989) "Minimalism, justification and non-monotony in deductive databases", Journal of Computer and System Sciences 38: 290-325. 4. Bruck G. (1991). Nonmonotonic reasoning: logical foundations of common sense. Cambridge University Press. 5. Bruck G., Dix J., Konolidzh K. (1997). Nonmonotonic Reasoning Review. CSLI Publications, Stanford. 6. M. Cadoli, M. Schaerf (1993) "An overview of the difficulty ends for non-monotonic logics" Logical Programming Journal 17: 127-60. 7. Donini F.M., Lenzerini M., Nardi D., Pyrri F., Schäerf M. (1990) "Nonmonotonic Reasoning," Artificial Intelligence Review 4: 163-210. 8. ML Ginsberg, ed. (1987) Readings in Non-Monotonic Reasoning. Los Alts CA: Morgan Cofman. 9. Horty J.F., 2001, "Nonmonotonic Logic", in Goble, Lou, editor, Blackwell's Philosophical Logic Reference Book. Blackwell 10. McDermott, Doyl J. Non- monotonic logic I // Artificial Intelligence. 1980. V. 13. R. 14 - 72. 11. Pospelov D.A. Situational management: theory and practice / Pospelov DA - M $\therefore$ Nauka, 1986. - 288 p. 12. Pospelov DA Principles of situational management // Izv. Academy of Sciences of the USSR. Technical cybernetics. 1971. - № 2. - p. 10-17. 13. Klykov Yu.I. Situational management of large systems / Klykov Yu.I. - M .: Energy, 1974. - 134 p. 14. Pospelov D.A. Situational management. Theory and Practice / Pospelov DA- M .: Science, 1986. - 288 p. 15. Osipov G.S. Semiotic Modeling: An Overview // In [4], pp. 51-72. 16. Finn V.K. Artificial Intelligence: Methodology, Applications, Philosophy = Artificial intelligence: methodology, applications, philosophy / scientific. ed. M.A. Mikheenkov. M .: KRASAND, 2011. 447 c. 17. Finn V.K. Plausible reasoning in intelligent systems such as DSM. Results of science and technology. Computer science. V. 15. M: 1991. pp.54-101. 